\title{
Molecular profiling, including TERT promoter mutations, of acral lentiginous melanomas
}

\author{
Vinicius de Lima Vazquez ${ }^{\mathrm{a}, \mathrm{b}}$, Anna L. Vicente ${ }^{\mathrm{a}}$, Adriana Carloni ${ }^{\mathrm{a}}$, \\ Gustavo Berardinelli ${ }^{\mathrm{a}}$, Paula Soares ${ }^{\mathrm{d}}$, Cristovam Scapulatempo ${ }^{\mathrm{a}, \mathrm{c}}$, \\ Olga Martinho ${ }^{\mathrm{a}, \mathrm{e}, \mathrm{f}}$ and Rui M. Reis $\mathrm{i}^{\mathrm{a}, \mathrm{e}, \mathrm{f}}$
}

Acral lentiginous melanoma (ALM) is the less common subtype with singular characterization. TERT (human telomerase reverse transcriptase) promoter mutations have being described as recurrent in melanomas and infrequent in ALM, but their real incidence and clinical relevance is unclear. The objectives of this study were to describe the prevalence of TERT promoter mutations in ALM, and correlate with the molecular profile of other drive genes and clinical features. Sixty-one samples from 48 patients with ALM were analyzed. After DNA isolation, the mutation profiles of the hotspot region of BRAF, NRAS, KIT, PDGFRA, and TERT genes were determined by PCR amplification followed by direct Sanger sequencing. KIT, PDGFRA, and VEGFR2 gene amplification was performed by quantitative PCR. Clinical information such as survival, clinical stage, and Breslow tumor classification were obtained from medical records. TERT promoter mutations were found in 9.3\% of the cases, BRAF in $10.3 \%$, NRAS in $7.5 \%, K I T$ in $\mathbf{2 0 . 7 \%}$, and PDGFRA in $\mathbf{1 4 . 8 \%}$ of ALM. None of the cases showed KIT, PDGFRA, or VEGFR2 gene amplification. We found an association between $K I T$ mutations and advanced Clark level (IV and V, $P=0.043$ ) and TERT promoter mutations with low mitotic index. No other significant

\section{Introduction}

Cutaneous melanoma is the most aggressive skin cancer, with a rising incidence worldwide in the past few decades [1]. Different from the main melanoma subtypes, usually diagnosed in white populations with fair skin and hair, the acral lentiginous melanoma (ALM) is an infrequent counterpart, accounting for less than $2 \%$ of all melanoma cases [2,3]. This subtype exhibits unique clinical characteristics, affecting only the palms of the hands, the soles of the feet, and the subungual area $[4,5]$. In regions with vast contingent of non-white population, such as Asia, Africa, and part of America, ALM is a major concern, as it occurs in populations and skin areas that are not generally at risk for skin cancer, leading frequently to late diagnosis and low survival rates [6-8]. In Brazil, a country with high miscegenated and heterogeneous population with African, European and indigenous heritage, ALM is prevalent in some geographic areas [9-11].

All supplementary digital content is available directly from the corresponding author.

0960-8931 Copyright (C) 2016 Wolters Kluwer Health, Inc. All rights reserved. associations were observed between mutation profile and patients' clinical features nor survival rates. Oncogenic $T E R T$ promoter mutations are present in a fraction of ALMs. No relevant associations were found between TERT mutation status and clinical/molecular features nor survival. Mutations of KIT and PDGFRA are the most common genetic alterations, and they can be therapeutic targets for these patients. Melanoma Res 26:93-99 Copyright (c) 2016 Wolters Kluwer Health, Inc. All rights reserved.

Melanoma Research 2016, 26:93-99

Keywords: acral lentiginous, melanoma, molecular profile, TERT promoter mutation

${ }^{a}$ Molecular Oncology Research Center, ${ }^{b}$ Department of Surgery, Melanoma and Sarcoma Unity, ' ${ }^{\mathrm{D}}$ epartment of Pathology, Barretos Cancer Hospital, Barretos, São Paulo, Brazil, Institute of Pathology and Molecular Immunology of University of Porto, (IPATIMUP), Porto, 'Life and Health Sciences Research Institute (ICVS), Health Sciences School, University of Minho and fICVS/3B's-PT Government Associate Laboratory, Braga, Portugal

Correspondence to Vinicius de Lima Vazquez, MD, PhD, Molecular Oncology Research Center, Barretos Cancer Hospital, Rua Antenor Duarte Villela, 1331, CEP 14784 400, Barretos, São Paulo, Brazil

Tel/fax: + 551733216600 ; e-mails: viniciusvazquez@gmail.com

Received 21 May 2015 Accepted 6 November 2015

Over the past few years we have witnessed a fast growth in molecular characterization of melanomas, with great emphasis in alterations of cell signaling pathways $[12,13]$. The mitogen-activated protein kinase pathway has a crucial role in melanoma development and progression $[12,14] . B R A F$, an intracellular serine-threonine kinase, is mutated in $\sim 60 \%$ of cutaneous melanomas $[12,15,16]$. Ninety-five percent of such cases result in a V600E mutation, which involves a valine to glutamic acid substitution at position 600 , which leads to a constitutive activation of the mitogen-activated protein kinase pathway $[12,14,17]$. Mutations are also frequent in another intracellular kinase, particularly in the NRAS gene, with a rate of $15-18 \%$ of mutated cases [12,14,17]. It has been reported that ALM exhibited a distinct molecular profile when compared with cutaneous melanoma [18]. In the ALM subtype, BRAF mutations are uncommon, and mutations were identified in upstream receptor tyrosine kinase, such as KIT (15-30\%) and PDGFRA (6.8\%) $[12,14,17]$. It was also reported that KIT and PDGFRA DOI: 10.1097/CMR.0000000000000222 
could be altered in ALM by gene amplification mechanisms of their 4p12 locus [18-20]. Besides these two oncogenes, this locus also harbors another important oncogene, KDR, also known as VEGFR2 (vascular endothelial growth factor receptor-2 gene) [21,22]. Importantly, many of the mutated molecules in ALM have emerged for therapeutic targets, such as BRAF, KIT/ PDGFR, and VEGFR2 [23-25].

Recently, another important cancer-related gene, telomerase reverse transcriptase (TERT), was described to be mutated in melanomas [26,27]. TERT encodes a subunit of telomerase that, together with other components, elongates the telomere maintaining genomic integrity. Its upregulation has being demonstrated in several human cancers, and the promoter region of the gene is considered the most regulatory element for telomerase expression. TERT promoter mutations, namely at positions c. $-124 \mathrm{C}>\mathrm{T}$ and c. $-146 \mathrm{C}>\mathrm{T}$, have being reported in up to $50 \%$ of cutaneous melanoma [26]. In ALM, the data are scarce, with few studies addressing its biological and clinical impacts [28-30].

In the present study, we intend to determine the frequency of hotspot TERT promoter mutations in a series of ALM melanomas. Furthermore, we aimed to assess other major molecular features, such as $B R A F, N R A S$, KIT, PDGFRA mutations, as well as amplification of 4q12 locus (KIT/PDGFRA/VEGFR2), and correlate with TERT mutation status and with ALM clinicopathological features.

\section{Materials and methods}

Sixty-one formalin-fixed paraffin-embedded tissues from 48 ALM patients were retrieved from the files of the Department of Pathology at Barretos Cancer Hospital. All the patients were diagnosed between 1999 and 2013. Primary tumor samples were obtained from 48 cases. Eleven cases also presented lymph node (LN) samples and in two cases we assessed the distant metastasis. All cases were re-evaluated by a pathologist who confirmed the diagnosis and identified the tumor region for further molecular analysis. The study was conducted according to the national and institutional ethical policies, and it was previously approved by the Local Ethics Committee (CEP-548/2011).

\section{DNA isolation from FFPE tissue}

DNA was obtained from formalin-fixed paraffinembedded tissue sections representative of the tumor lesions, as previously described with some modifications [31]. Briefly, serially $10-\mu \mathrm{m}$-thick unstained sections of paraffin blocks were sectioned and one haematoxylin and eosin (H\&E) section was used for identification and selection of the tumor area, which was macrodissected into a microfuge tube using a sterile needle $(25 \mathrm{G}-$ $0.5 \mathrm{~mm}$, Neolus, Terumo Corporation, Tokyo, Japan). The macrodissected tissue was deparaffinized by a serial wash with xylol and ethanol (100-70-50\%) and allowed to air-dry. DNA was extracted using Qiagen's QIAamp DNA Micro Kit (Qiagen, Hilden, Germany) according to the manufacturer's instructions and quantified by NanoDrop 2000 (Thermo Scientific, Waltham, Massachusetts, USA). DNA samples were stored at $-20^{\circ} \mathrm{C}$ until further genetic analysis.

\section{Mutation analysis of TERT, KIT, PDGFRA, and BRAF and NRAS hotspot regions}

The analysis of hotspot mutations of TERT promoter regions (contained the sites of c. $-124: \mathrm{C}>\mathrm{T}$ and c. $-146: \mathrm{C}>\mathrm{T}$ ), KIT (exons 9, 11, 13, and 17), PDGFRA [12,14,18], BRAF (exon 15), and NRAS (codon12/13, 61), was performed by PCR followed by direct Sanger sequencing, as described previously [28,31-33]. Briefly, using specific pairs of primers (Supplementary Table 1), the target regions were amplified by PCR with an initial denaturation at $95^{\circ} \mathrm{C}$ for $15 \mathrm{~min}$, followed by 40 cycles of $95^{\circ} \mathrm{C}$ denaturation for $45 \mathrm{~s}$, specific annealing temperature for $90 \mathrm{~s}$ and $72^{\circ} \mathrm{C}$ elongation for $45 \mathrm{~s}$, and $72^{\circ} \mathrm{C}$ final elongation for $7 \mathrm{~min}$, in a Verity PCR machine (Applied Biosystems, Carlsbad, California, USA). Amplification of PCR products was confirmed by gel electrophoresis. Sequencing PCR was performed using a Big Dye terminator v3.1 cycle sequencing ready reaction kit (Applied Biosystems) and the ABI PRISM $3500 \mathrm{xL}$ Genetic Analyzer (Applied Biosystems). All mutated cases were confirmed with a second PCR followed by sequencing.

\section{Gene amplification analysis of KIT, PDGFRA, and VEGFR2}

KIT, PDGFRA, and VEGFR2 gene amplification was performed by quantitative real-time PCR with LightCycler (Roche Molecular Biochemicals, Mannheim, Germany), using fluorescent hybridization probes and fluorescence resonance energy transfer for the detection of PCR amplification product, as previously described [34,35]. In all assays, appropriate positive and negative controls of 4q12 loci amplification were included [36]. These controls had also been previously assessed by other methodologies, such as array-CGH and CISH $[34,36,37]$.

\section{Statistical analysis}

The SPSS 19.0 software (IBM Corp., Armonk, New York, USA) was used for all statistics analyses. To identify associations among clinicopathological characteristics and the molecular alterations, and to compare the prevalence of molecular findings with the previous reports, the Fisher exact test was used. Associations of the same variables with specific cancer survival were analyzed by the Kaplan-Meier method to estimate specific cancer survival, with log-rank testing used to evaluate differences between curves. The $P$-value established for the statistics significance was up to 0.05 . 
Table 1 Demographic and clinicopathological features of 48 acral lentiginous melanomas

\begin{tabular}{lc}
\hline Characteristics & $n(\%)$ \\
\hline Sex & \\
Male & $23(47.9)$ \\
Female & $25(52.1)$ \\
Age [mean (SD)] & $62(14.8)$ \\
Skin & \\
White & $32(66.7)$ \\
Pigmented & $15(31.3)$ \\
Not available & $1(2)$ \\
Anatomical location & \\
Hands & $3(6.3)$ \\
Feet & $45(93.7)$ \\
Breslow depth (mm) & \\
Up to 1 & $4(8.3)$ \\
1.1-2 & $7(14.6)$ \\
$2.1-4$ & $16(33.3)$ \\
More than 4 & $17(35.4)$ \\
Not available & $4(8.3)$ \\
Ulceration & \\
Yes & $31(64.6)$ \\
No & $10(20.8)$ \\
Not available & $7(14.6)$ \\
Mitotic rate (mm $\left.{ }^{2}\right)$ & \\
O & $0(0)$ \\
1 & $11(22.9)$ \\
>1 & $37(52.1)$ \\
Not available & $12(25)$ \\
TNM stage & \\
I & $5(10.4)$ \\
II & $22(45.8)$ \\
III & $17(35.4)$ \\
IV & $4(8.3)$ \\
\hline &
\end{tabular}

\section{Results}

\section{Clinicopathological features}

The characteristics of the patients are shown in Table 1 . The age ranged from 26 to 85 years old (mean $62 \pm 14.8$ ), and men and women had similar distribution. One-third of the cases presented non-white skin phenotype. Primary lesions were thick and ulcerated in most cases and arose only on the hands in three $(6.3 \%)$ cases. Localized disease represented half of the cases. Breslow tumor thickness ranged from 0.62 to $20.0 \mathrm{~mm}$, with a median of $4.9( \pm 4.6)$. Five-year-specific cancer survival rate for all patients was $51.5 \%$. Follow-up ranged from 2 to 174 months, with a mean of $35.5( \pm 30.4)$ and a median of 29.6. At the last evaluation, 20 patients $(41.7 \%)$ were alive without disease, nine were alive with disease (18.8\%), 17 were dead because of melanoma (35.4\%), and two were dead because of other causes $(4.1 \%)$.
Table 3 Exons/codons location of the mutated genes

\begin{tabular}{ll}
\hline Mutation & $n(\%)$ \\
\hline $\begin{array}{l}\text { TERT } \\
\text { C. }-146 \text { C > T }\end{array}$ \\
BRAF \\
$\quad$ Exon 15 (V600E) & $4(100)$ \\
NRAS & $5(100)$ \\
Codon 61 & \\
KIT & $3(100)$ \\
Exon 9 & \\
Exon 11 & $1(16.6)$ \\
Exon 13 & $3(50)$ \\
Exon 17 & $1(16.6)$ \\
PDGFRA & $1(16.6)$ \\
Exon 12 & \\
Exon 14 & $3(60)$ \\
Exon 18 & $1(20)$ \\
\hline
\end{tabular}

TERT, telomerase reverse transcriptase.

\section{Molecular profile}

Because of the low amount and/or poor DNA quality yield in some samples, we were not able to obtain molecular profiles from all ALM cases. Table 2 summarizes the molecular results. In primary tumors, we observed the presence of $7.0 \%$ (3/43) TERT mutations, harboring the c. $-146 \mathrm{C}>\mathrm{T}$ mutation in all cases (Tables 2 and 3 ). We found a frequency of mutations of $20.7 \%$ for KIT, $14.8 \%$ for PDGFRA, $7.5 \%$ for NRAS, and $10.3 \%$ for $B R A F$ genes (Table 2). KIT, PDGFRA, and $V E G F R 2$ copy numbers were normal in all analyzed cases. One case exhibited two mutations in PDGFRA: one at exon 12 and another on exon 14 (Table 3). In the comparison of primary and $\mathrm{LN}$ or skin metastasis, we observed a similar molecular status, except in one case that showed TERT mutated only in the LN metastasis (Table 2). One case exhibited the same BRAF mutation in both primary and LN metastases (Table 2). The cooccurrence of mutations across specimens is demonstrated in Fig. 1. Only BRAF mutations were exclusive. $N R A S$ was mutated mutually only in one case with PDGFRA mutation, and the same was observed with TERT and KIT; KIT and PDGFRA presented comutated with two other mutations (Fig. 1).

\section{Clinicopathological and molecular associations}

We found a significant association between KIT mutation status and higher Clark levels (Table 4). We also observed an association between TERT mutations and lower mitosis index (Table 4). There were no significant

Table 2 Molecular profile of acral lentiginous melanomas

\begin{tabular}{|c|c|c|c|c|c|c|c|c|}
\hline \multirow[b]{2}{*}{ Patient group } & \multicolumn{5}{|c|}{ Mutations [n/N (\%)] } & \multicolumn{3}{|c|}{ Gene amplification $[n / N(\%)]$} \\
\hline & TERT & KIT & PDGFRA & NRAS & BRAF & KIT & PDGFRA & VEGFR2 \\
\hline Primary & $3 / 43(7.0)$ & $6 / 29(20.7)$ & $4 / 27(14.8)$ & $3 / 40(7.5)$ & 4/39 (10.3) & $0 / 35(0)$ & $0 / 36(0)$ & $0 / 8(0)$ \\
\hline Lymph node & $1 / 10(10)$ & $0 / 10(0)$ & $0 / 8(0)$ & $0 / 10(0)$ & $1 / 11(9.1)$ & $0 / 10(0)$ & $0 / 10(0)$ & $0 / 2(0)$ \\
\hline Metastasis & $0 / 2(0)$ & $0 / 2(0)$ & $0 / 2(0)$ & $0 / 2(0)$ & $0 / 2(0)$ & $0 / 2(0)$ & $0 / 2(0)$ & $0 / 0(0)$ \\
\hline
\end{tabular}

TERT, telomerase reverse transcriptase; VEGFR2, vascular endothelial growth factor receptor-2. 


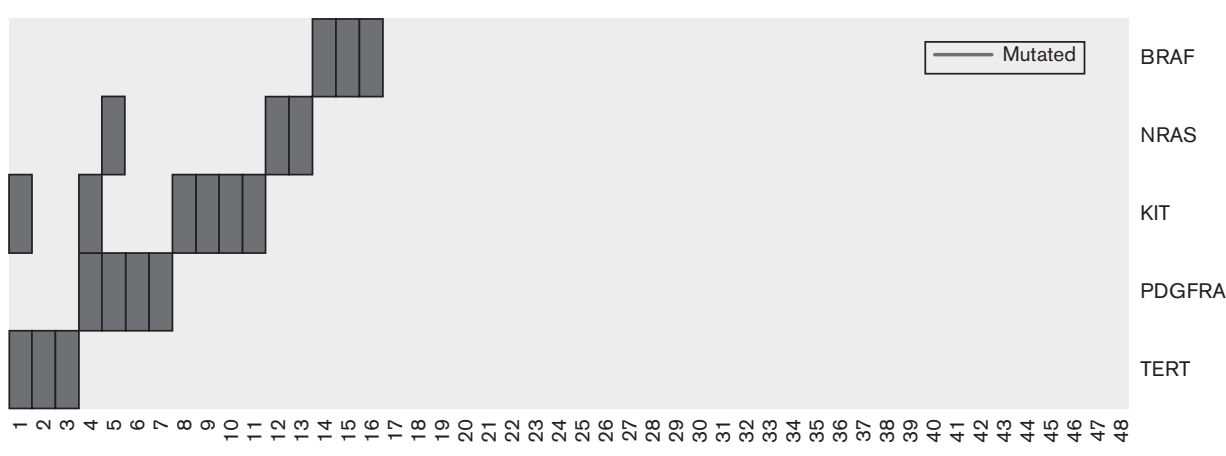

Distribution of BRAFINRAS/KITIPDGFRA and TERT promoter mutations of 48 acral lentiginous melanomas. TERT, telomerase reverse transcriptase.

Table 4 Association of molecular profile with clinicopathological features in acral lentiginous melanomas

\begin{tabular}{|c|c|c|c|c|c|c|c|c|c|c|}
\hline \multirow[b]{3}{*}{ Variables } & \multicolumn{10}{|c|}{$n(\%)$} \\
\hline & \multicolumn{2}{|c|}{ BRAF } & \multicolumn{2}{|c|}{ NRAS } & \multicolumn{2}{|c|}{ KIT } & \multicolumn{2}{|c|}{ PDGFRA } & \multicolumn{2}{|c|}{ TERT } \\
\hline & WT & Mutated & WT & Mutated & WT & Mutated & WT & Mutated & WT & Mutated \\
\hline \multicolumn{11}{|l|}{ Breslow (mm) } \\
\hline Up to 1 & $2(5.7)$ & $0(0)$ & $3(8.1)$ & $0(0)$ & $1(4.3)$ & $0(0)$ & $1(4.3)$ & $0(0)$ & $2(5.1)$ & $1(25)$ \\
\hline $1.1-2.0$ & $5(14.3)$ & $1(25)$ & $6(16.2)$ & $0(0)$ & $4(17.4)$ & $1(16.7)$ & $4(17.4)$ & $1(25)$ & 7 (17.9) & $0(0)$ \\
\hline $2.1-4.0$ & 12 (34.3) & $2(50)$ & 12 (32.4) & $3(100)$ & $9(39.1)$ & $3(50)$ & $10(43.5)$ & $2(50)$ & 13 (33.3) & $1(25)$ \\
\hline More than 4 & $13(37.1)$ & $1(25)$ & $13(35.1)$ & $0(0)$ & $6(36.1)$ & 2 (33.3) & $6(26.1)$ & $1(25)$ & $14(35.9)$ & $2(50)$ \\
\hline Unknown & $3(8.6)$ & $\begin{array}{l}0(0) \\
P=0.899\end{array}$ & $3(8.1)$ & $\begin{array}{l}0(0) \\
P=0.248\end{array}$ & $3(13)$ & $\begin{array}{c}0(0) \\
P=0.886\end{array}$ & $2(8.7)$ & $\begin{array}{c}0(0) \\
P=1.00\end{array}$ & $3(7.7)$ & $\begin{array}{c}0(0) \\
P=0.594\end{array}$ \\
\hline \multicolumn{11}{|l|}{ Clark } \\
\hline II & 1 (3.1) & $0(0)$ & $1(2.9)$ & $0(0)$ & - & - & - & - & $1(2.8)$ & $0(0)$ \\
\hline III & $2(6.3)$ & $0(0)$ & $3(8.8)$ & $0(0)$ & $3(15)$ & $0(0)$ & $2(9.5)$ & $1(25)$ & $4(11.1)$ & $1(25)$ \\
\hline IV & $16(50)$ & $3(75)$ & 17 (50.0) & $3(100)$ & $14(70)$ & 2 (33.3) & $12(57.1)$ & $3(75)$ & $19(52.8)$ & $1(25)$ \\
\hline V & $13(40.6)$ & $1(25)$ & $13(38.2)$ & $0(0)$ & $3(15)$ & $4(66.7)$ & 7 (3з.3) & $0(0)$ & 12 (33.3) & $2(50)$ \\
\hline & & $P=0.736$ & & $P=0.428$ & & $P=0.043$ & & $P=0.400$ & & $P=0.491$ \\
\hline \multicolumn{11}{|l|}{ Ulceration } \\
\hline Absent & $6(19.4)$ & $0(0)$ & $6(18.8)$ & $2(66.6)$ & $4(19)$ & 2 (33.3) & $5(22.7)$ & $1(25)$ & $8(22.9)$ & 1 (33.3) \\
\hline Present & $25(80.6)$ & $4(100)$ & $26(81.2)$ & 1 (33.3) & $17(81)$ & $4(66.7)$ & $17(77.3)$ & $3(75)$ & $27(77.1)$ & $2(66.7)$ \\
\hline & & $P=0.581$ & & $P=1.00$ & & $P=0.588$ & & $P=1.00$ & & $P=0.164$ \\
\hline \multicolumn{11}{|l|}{ Mitosis } \\
\hline 1 & $6(22.2)$ & $2(66.7)$ & $9(32.1)$ & $0(0)$ & $5(27.8)$ & 2 (33.3) & 7 (35) & $0(0)$ & $6(20)$ & $3(100)$ \\
\hline$>1$ & $21(77.8)$ & 1 (33.3) & $19(67.9)$ & $3(100)$ & $13(72.2)$ & $4(66.7)$ & $13(65)$ & $3(100)$ & $24(80)$ & $0(0)$ \\
\hline & & $P=0.166$ & & $P=0.537$ & & $P=1.00$ & & $P=0.526$ & & $P=\mathbf{0 . 0 1 5}$ \\
\hline \multicolumn{11}{|l|}{ TNM stage } \\
\hline 1 & $3(8.6)$ & $0(0)$ & $4(10.8)$ & $0(0)$ & $2(8.7)$ & $0(0)$ & $1(4.3)$ & $1(25)$ & $4(10.3)$ & $1(25)$ \\
\hline II & $17(48.6)$ & $2(50)$ & $18(48.6)$ & $2(66.7)$ & $10(43.5)$ & $4(66.7)$ & $13(56.5)$ & $1(25)$ & $18(46.2)$ & $1(25)$ \\
\hline III & 11 (31.4) & $2(50)$ & 12 (32.4) & 1 (33.3) & $8(34.8)$ & 2 (33.3) & $7(30.4)$ & $2(50)$ & 13 (33.3) & $2(50)$ \\
\hline \multirow[t]{2}{*}{ IV } & $4(11.4)$ & $0(0)$ & $3(8.1)$ & $0(0)$ & $3(13)$ & $0(0)$ & $2(8.7)$ & $0(0)$ & $4(10.3)$ & $0(0)$ \\
\hline & & $P=1.00$ & & $P=1.00$ & & $P=0.776$ & & $P=0.440$ & & $P=0.751$ \\
\hline
\end{tabular}

Fisher's exact test was applied in all cases.

Bold number indicates significant association.

TERT, telomerase reverse transcriptase.

differences in the survival rates according to TERT, $B R A F, N R A S, K I T$, and PDGFRA mutation status in the univariate analysis (data not shown).

\section{Discussion}

In the present study, we described for the first time the molecular profile of Brazilian acrolentigenous melanomas. We showed that Brazilian patients exhibited a similar profile to the one described in the international literature [12,18-20,24,28-30,38-64] (Table 5).
We found that TERT c. $-146 \mathrm{C}>\mathrm{T}$ promoter mutation is present in $9.3 \%$ of patients, and this frequency was in concordance with the reported $7.6 \%(7 / 92)(P=0.732)$ (Table 5). However, our study represents the larger analysis of the gene hotspot region of TERT in this melanoma subtype (Table 5). Previous studies in thyroid cancer and skin melanomas suggested an association of TERT mutation with other molecular alterations, such as $B R A F$ [28]. In superficial melanomas, thyroid cancer, and gliomas, TERT promoter mutations have been also reported to be 
Table 5 Summary of molecular features of acral lentiginous melanomas

\begin{tabular}{|c|c|c|c|c|c|c|c|c|c|}
\hline \multirow[b]{2}{*}{ References } & \multirow[b]{2}{*}{ Country } & \multicolumn{5}{|c|}{ Mutations $[n / N(\%)]$} & \multicolumn{3}{|c|}{ Gene amplification $[n / N(\%)]$} \\
\hline & & TERT & KIT & PDGFRA & NRAS & BRAF & KIT & PDGFRA & VEGFR2 \\
\hline This study & Brazil & $4 / 43(9.3)$ & $6 / 29(20.7)$ & $4 / 27(14.8)$ & $3 / 40(7.5)$ & 4/39 (10.3) & 0/35 (0) & $0 / 36(0)$ & $0 / 8(0)$ \\
\hline Heidenreich et al. [29] & Spain & $4 / 42(9.5)$ & NA & NA & $2 / 38(5.3)$ & $12 / 30(28.6)$ & NA & NA & NA \\
\hline Pozzobon et al. [38] & Spain & NA & NA & NA & $0 / 10(0)$ & $2 / 10(20)$ & NA & NA & NA \\
\hline Liau et al. [30] & China & 2/32 (6.25) & NA & NA & NA & NA & NA & NA & NA \\
\hline Dai et al. [39] & China & NA & NA & 9/132 (9.8) & NA & NA & NA & NA & NA \\
\hline Vinagre et al. [28] & Portugal & $1 / 14(7.1)$ & NA & NA & NA & $2 / 14(14.3)$ & NA & NA & NA \\
\hline Hodi et al. [20] & Multicenter & NA & 2/6 (33.3) & NA & NA & NA & $4 / 4(100)$ & NA & NA \\
\hline Zebary et al. [41] & Sweden & NA & $13 / 88(14.8)$ & NA & $13 / 88(14.8)$ & $15 / 88(17.0)$ & NA & NA & NA \\
\hline Greaves et al. [48] & USA & NA & NA & NA & NA & $18 / 111(16.2)$ & NA & NA & NA \\
\hline Dai et al. [39] & China & NA & $9 / 39(23.1)$ & NA & NA & NA & NA & NA & NA \\
\hline Lin et al. [40] & China & NA & $0 / 20(0)$ & NA & NA & NA & NA & NA & NA \\
\hline Puig-Butillé et al. [42] & Spain & NA & NA & NA & $3 / 17(17.6)$ & $0 / 17(0)$ & NA & NA & NA \\
\hline Minor et al. [24] & USA & NA & $3 / 22(13.6)$ & NA & $6 / 22(27.3)$ & $7 / 22(31.8)$ & $6 / 22(27.3)$ & NA & NA \\
\hline Si et al. [47] & China & NA & NA & NA & $13 / 148(8.8)$ & $23 / 148(15.5)$ & NA & NA & NA \\
\hline Ashida et al. [43] & Japan & NA & $4 / 44(9.1)$ & NA & NA & NA & NA & NA & NA \\
\hline Jakob et al. [44] & USA & NA & NA & NA & $7 / 44(15.9)$ & $6 / 44(13.6)$ & NA & NA & NA \\
\hline Yun et al. [45] & Korea & NA & $4 / 40(10)$ & NA & NA & NA & $7 / 20(35.0)$ & NA & NA \\
\hline Kong et al. [46] & China & NA & $23 / 193(11.9)$ & NA & NA & NA & $14 / 193(7.3)$ & NA & NA \\
\hline Handolias and colleagues $[49,50]$ & Australia & NA & $2 / 6(33.3)$ & NA & NA & NA & NA & NA & NA \\
\hline Terada [51] & Japan & NA & $1 / 2(50)$ & $0 / 2(0)$ & NA & NA & NA & NA & NA \\
\hline Handolias and colleagues $[49,50]$ & Australia & NA & $1 / 16(6.25)$ & NA & NA & NA & NA & NA & NA \\
\hline Torres-Cabala et al. [52] & USA & NA & $5 / 39(12.8)$ & NA & NA & NA & NA & NA & NA \\
\hline Ashida et al. [53] & Japan & NA & $2 / 16(12.5)$ & NA & $0 / 22(0)$ & $3 / 22(13.6)$ & 3/16 (18.8) & NA & NA \\
\hline Curtin et al. [54] & USA & NA & NA & $0 / 7(0)$ & NA & NA & NA & $3 / 7(42.9)$ & NA \\
\hline Akslen et al. [55] & Africa & NA & NA & NA & $3 / 26(11.5)$ & $1 / 25(4.0)$ & NA & NA & NA \\
\hline Beadling et al. [56] & USA & NA & $3 / 13(23.1)$ & NA & $1 / 9(11.1)$ & $2 / 12(16.7)$ & $3 / 11(27.3)$ & NA & NA \\
\hline Takata et al. [57] & Japan & NA & NA & NA & $1 / 6(16.7)$ & $2 / 8(24.05)$ & NA & NA & NA \\
\hline Liu et al. [59] & Australia & NA & NA & NA & NA & $0 / 6(0)$ & NA & NA & NA \\
\hline Curtin et al. [19] & USA & NA & $3 / 28(10.7)$ & NA & $0 / 10(0)$ & $1 / 10(10.0)$ & $2 / 28(7.1)$ & NA & NA \\
\hline Saldanha et al. [18] & UK & NA & NA & NA & $9 / 19(47.4)$ & $2 / 21$ (9.5) & NA & NA & NA \\
\hline Davison et al. [60] & USA & NA & NA & NA & NA & $0 / 3(0)$ & NA & NA & NA \\
\hline Curtin et al. [12] & Multicenter & NA & NA & NA & $3 / 35(8.6)$ & $7 / 35(20.0)$ & NA & NA & NA \\
\hline Takata et al. [58] & Japan & NA & NA & NA & $1 / 28(3.6)$ & $3 / 28(10.8)$ & NA & NA & NA \\
\hline Lang and MacKie [61] & UK & NA & NA & NA & NA & $2 / 17(11.8)$ & NA & NA & NA \\
\hline Sasaki et al. [62] & Germany & NA & NA & NA & $0 / 15(0)$ & $5 / 15$ (33.3) & NA & NA & NA \\
\hline Reifenberger et al. [63] & Germany & NA & NA & NA & $1 / 4(25.0)$ & $2 / 4(50.0)$ & NA & NA & NA \\
\hline Maldonado et al. [64] & USA/Japan & NA & NA & NA & NA & $4 / 30(13.3)$ & NA & NA & NA \\
\hline All the referred studies & - & $7 / 92(7.6)$ & $75 / 572(13.1)$ & $9 / 145(6.2)$ & $63 / 544(11.6)$ & $119 / 724(16.4)$ & $39 / 294(13.3)$ & $3 / 7(42.9)$ & NA \\
\hline Total & - & $11 / 131(8.4)$ & $81 / 601(13.5)$ & $13 / 168(7.7)$ & $66 / 581(11.4)$ & $123 / 759(16.2)$ & $39 / 329(11.9)$ & $3 / 43(7.0)$ & $0 / 8(0)$ \\
\hline
\end{tabular}

NA, not available; TERT, telomerase reverse transcriptase; VEGFR2, vascular endothelial growth factor receptor-2.

associated with older patients and worse patient prognosis [65]. In our study, we did not observe such molecular and clinical associations in acrolentigenous melanomas. The association with low mitotic index could be related to better prognosis, but the small number of mutated cases needs further confirmation in a larger series.

Acrolentigenous melanomas are known to harbor a distinct molecular profile of superficial melanomas. Compelling evidence showed the paramount role of KIT and PDGFRA alterations in the melanoma subtype [66]. In the present study, we found a mutation frequency of 16.7 and $12.5 \%$ for $K I T$ and PDGFRA, respectively. Among KIT mutations, 50\% were located on exon 11 and the others were distributed among the other exons $[9,13$, 17], whereas $60 \%$ of PDGFRA mutations were located on exon 12 and the others were distributed on exons 14 and 18. These mutation rates are in accordance with previous descriptions of $13.1 \%(75 / 572)$ and $6.2 \%$ (9/145) $(P=0.145$ and 0.108$)$ (Table 5). Some authors have identified KIT gene amplification as an alternative mechanism for KIT upregulation in these tumors [18-20]. However, we did not find any case with KIT gene amplification using quantitative real-time PCR, a very sensitive and specific methodology, previously optimized by us and reported by our group and other groups $[34,36,67,68]$. We observed an association between KIT mutation and higher Clark staging, indicating that KIT could be associated with a more aggressive disease. The presence of KIT and PDGFRA alterations, namely mutations, has an important therapeutic impact. It has been shown that some melanoma patients exhibiting KIT/PDGFRA mutations, rather than gene amplification, can benefit from imatinib-based targeted therapy [69]. Recently, KIT/PDGFRA mutations have been found as targets for other small inhibitors, such as crenolanib and nilotinib [39,70]. Therefore, we can anticipate that between 15 and $20 \%$ of Brazilian acrolentigenous melanoma patients would benefit from these above-mentioned therapeutic modalities. 
We also analyzed in this study the frequency of NRAS (codon12/13 and 61) and BRAF (exon 15) hotspot mutations. We found that NRAS was mutated in $6.3 \%$ of cases. This frequency was somehow below what is reported worldwide, which is above $11 \%$ (63/544) $(P=0.787)$ of cases (Table 5). However, NRAS frequency reports range from 0 to $47 \%$ (Table 5); therefore, there is not really a consensus in the literature, and this could be because of the distinct sizes of series analyzed in each study, or it could reflect the differences between populations.

With regard to $B R A F$, we observed the presence of $10.6 \%$ (all V600E) of mutated cases. This result is in line with the reported $(16.4 \%$ - 119/724) $(P=0.639)$ (Table 5), where the values range from 0 to $33 \%$ of $B R A F$ mutated cases. $B R A F$ mutations were exclusive events. Besides the low frequency of all mutations, they were mutually present at least in one-third of the cases, except for the $B R A F$, corroborating the high spectrum of melanoma mutations reported.

In conclusion, we have molecularly characterized a series of 48 ALMs. We have shown that less than $10 \%$ of patients harbor the recurrent TERT promoter mutation, and KIT represents the most mutated gene $(21 \%)$, followed by PDGFRA (15\%), in this series. These results could help in the selection of other alternative and potential therapeutic options for Brazilian acral lentiginous melanoma patients.

\section{Acknowledgements}

This project was supported by FAPESP - Brazil (2012/4194-1) to Vinicius de Lima Vazquez.

\section{Conflicts of interest}

There are no conflicts of interest.

\section{References}

1 Erdmann F, Lortet-Tieulent J, Schuz J, Zeeb H, Greinert R, Breitbart EW, et al. International trends in the incidence of malignant melanoma 1953-2008 are recent generations at higher or lower risk? Int J Cancer 2013; 132:385-400.

2 Katalinic A, Kunze U, Schäfer T. Epidemiology of cutaneous melanoma and non-melanoma skin cancer in Schleswig-Holstein, Germany: incidence, clinical subtypes, tumour stages and localization (epidemiology of skin cancer). Br J Dermatol 2003; 149:1200-1206.

3 Bradford PT, Goldstein AM, McMaster ML, Tucker MA. Acral lentiginous melanoma: incidence and survival patterns in the United States, 1986-2005. Arch Dermatol 2009; 145:427-434.

4 Clark WH Jr, From L, Bernardino EA, Mihm MC. The histogenesis and biologic behavior of primary human malignant melanomas of the skin. Cancer Res 1969; 29:705-727.

5 McGovern VJ, Mihm MC Jr, Bailly C, Booth JC, Clark WH Jr, Cochran AJ, et al. The classification of malignant melanoma and its histologic reporting. Cancer 1973; 32:1446-1457.

6 Hudson DA, Krige JE. Melanoma in black South Africans. J Am Coll Surg 1995; 180:65-71.

7 Kabigting FD, Nelson FP, Kauffman CL, Popoveniuc G, Dasanu CA, Alexandrescu DT. Malignant melanoma in African-Americans. Dermatol Online J 2009; 15:3.

8 Chang JW. Acral melanoma: a unique disease in Asia. JAMA Dermato/ 2013; 149:1272-1273.
9 Brandão FV, Pereira AF, Gontijo B, Bittencourt FV. Epidemiological aspects of melanoma at a university hospital dermatology center over a period of 20 years. An Bras Dermatol 2013; 88:344-353.

10 Vilanova CM, Lages RB, Ribeiro SM, Almeida IP, Santos LG, Vieira SC. Epidemiological and histopathological profile of cutaneous melanoma at a center in northeastern Brazil from 2000 to 2010. An Bras Dermatol 2013; 88:545-553.

11 Vazquez Vde L, Silva TB, Vieira Mde A, de Oliveira AT, Lisboa MV, de Andrade DA, et al. Melanoma characteristics in Brazil: demographics, treatment, and survival analysis. BMC Res Notes 2015; 8: ():4.

12 Curtin JA, Fridlyand J, Kageshita T, Patel HN, Busam KJ, Kutzner H, et al. Distinct sets of genetic alterations in melanoma. N Engl J Med 2005; 353:2135-2147.

13 Bello DM, Ariyan CE, Carvajal RD. Melanoma mutagenesis and aberrant cell signaling. Cancer Control 2013; 20:261-281.

14 Gray-Schopfer V, Wellbrock C, Marais R. Melanoma biology and new targeted therapy. Nature 2007; 445:851-857.

15 Davies H, Bignell GR, Cox C, Stephens P, Edkins S, Clegg S, et al. Mutations of the BRAF gene in human cancer. Nature 2002; 417:949-954.

16 Pollock PM, Meltzer PS. A genome-based strategy uncovers frequent BRAF mutations in melanoma. Cancer Cell 2002; 2:5-7.

17 Davies MA, Gershenwald JE. Targeted therapy for melanoma: a primer. Surg Oncol Clin N Am 2011; 20:165-180.

18 Saldanha G, Potter L, Daforno P, Pringle JH. Cutaneous melanoma subtypes show different BRAF and NRAS mutation frequencies. Clin Cancer Res 2006; 12:4499-4505.

19 Curtin JA, Busam K, Pinkel D, Bastian BC. Somatic activation of KIT in distinct subtypes of melanoma. J Clin Oncol 2006; 24:4340-4346.

20 Hodi FS, Corless CL, Giobbie-Hurder A, Fletcher JA, Zhu M, MarinoEnriquez $A$, et al. Imatinib for melanomas harboring mutationally activated or amplified KIT arising on mucosal, acral, and chronically sun-damaged skin. J Clin Oncol 2013; 31:3182-3190.

21 Yin LY, Wu Y, Ballinger CA, Patterson C. Genomic structure of the human KDR/flk-1 gene. Mamm Genome 1998; 9:408-410.

22 Holtkamp N, Ziegenhagen N, Malzer E, Hartmann C, Giese A, von Deimling $A$. Characterization of the amplicon on chromosomal segment $4 q 12$ in glioblastoma multiforme. Neuro Oncol 2007; 9:291-297.

23 Flaherty KT, Infante JR, Daud A, Gonzalez R, Kefford RF, Sosman J, et al. Combined BRAF and MEK inhibition in melanoma with BRAF V600 mutations. N Engl J Med 2012; 367:1694-1703.

24 Minor DR, Kashani-Sabet M, Garrido M, O'Day SJ, Hamid O, Bastian BC. Sunitinib therapy for melanoma patients with KIT mutations. Clin Cancer Res 2012; 18:1457-1463.

25 Johansson I, Aaltonen KE, Ebbesson A, Grabau D, Wigerup C, Hedenfalk I, Rydén L. Increased gene copy number of KIT and VEGFR2 at $4 \mathrm{q} 12$ in primary breast cancer is related to an aggressive phenotype and impaired prognosis. Genes Chromosomes Cancer 2012; 51:375-383.

26 Horn S, Figl A, Rachakonda PS, Fischer C, Sucker A, Gast A, et al. TERT promoter mutations in familial and sporadic melanoma. Science 2013; 339:959-961.

27 Huang FW, Hodis E, Xu MJ, Kryukov GV, Chin L, Garraway LA. Highly recurrent TERT promoter mutations in human melanoma. Science 2013 339:957-959.

28 Vinagre J, Almeida A, Pópulo H, Batista R, Lyra J, Pinto V, et al. Frequency of TERT promoter mutations in human cancers. Nat Commun 2013; 4:2185.

29 Heidenreich B, Rachakonda PS, Hemminki K, Kumar R. TERT promoter mutations in cancer development. Curr Opin Genet Dev 2014; 24:30-37.

30 Liau JY, Tsai JH, Jeng YM, Chu CY, Kuo KT, Liang CW. TERT promoter mutation is uncommon in acral lentiginous melanoma. J Cutan Pathol 2014; 41:504-508.

31 Yamane LS, Scapulatempo-Neto C, Alvarenga L, Oliveira CZ, Berardinelli GN, Almodova $\mathrm{E}$, et al. KRAS and BRAF mutations and MSI status in precursor lesions of colorectal cancer detected by colonoscopy. Oncol Rep 2014; 32:1419-1426.

32 Martinho O, Gouveia A, Viana-Pereira M, Silva P, Pimenta A, Reis RM, Lopes JM. Low frequency of MAP kinase pathway alterations in KIT and PDGFRA wild-type GISTs. Histopathology 2009; 55:53-62.

33 Campanella NC, Celestino R, Pestana A, Scapulatempo-Neto C, de Oliveira AT, Brito MJ, et al. Low frequency of TERT promoter mutations in gastrointestinal stromal tumors (GISTs). Eur J Hum Genet 2015; 23:877-879.

34 Gomes AL, Reis-Filho JS, Lopes JM, Martinho O, Lambros MB, Martins A, et al. Molecular alterations of KIT oncogene in gliomas. Cell Oncol 2007; 29:399-408.

35 Martinho O, Longatto-Filho A, Lambros MB, Martins A, Pinheiro C, Silva A, et al. Expression, mutation and copy number analysis of platelet-derived 
growth factor receptor A (PDGFRA) and its ligand PDGFA in gliomas. $\mathrm{Br} \mathrm{J}$ Cancer 2009; 101:973-982.

36 Martinho O, Silva-Oliveira R, Miranda-Gonçalves V, Clara C, Almeida JR, Carvalho $A L$, et al. In vitro and in vivo analysis of RTK inhibitor efficacy and identification of its novel targets in glioblastomas. Trans/ Oncol 2013; 6:187-196.

37 Martinho O, Longatto-Filho A, Lambros MB, Martins A, Pinheiro C, Silva A, et al. Expression, mutation and copy number analysis of platelet-derived growth factor receptor A (PDGFRA) and its ligand PDGFA in gliomas. $\mathrm{Br} \mathrm{J}$ Cancer 2009; 101:973-982.

38 Pozzobon FC, Puig-Butillé JA, González-Alvarez T, Carrera C, Aguilera P Alos L, et al. Dermoscopic criteria associated with BRAF and NRAS mutation status in primary cutaneous melanoma. $\mathrm{Br} J$ Dermatol 2014; 171:754-759.

39 Dai J, Kong Y, Si L, Chi Z, Cui C, Sheng X, et al. Large-scale analysis of PDGFRA mutations in melanomas and evaluation of their sensitivity to tyrosine kinase inhibitors imatinib and crenolanib. Clin Cancer Res 2013; 19:6935-6942

40 Lin YC, Chang YM, Ho JY, Lin HC, Tsai YM, Chiang CP, et al. C-kit expression of melanocytic neoplasm and association with clinicopathological parameters and anatomic locations in Chinese people. Am J Dermatopathol 2013; 35:569-575.

41 Zebary A, Omholt K, Vassilaki I, Höiom V, Lindén D, Viberg L, et al. KIT, NRAS, BRAF and PTEN mutations in a sample of Swedish patients with acral lentiginous melanoma. J Dermatol Sci 2013; 72:284-289.

42 Puig-Butillé JA, Badenas C, Ogbah Z, Carrera C, Aguilera P, Malvehy J, Puig $S$. Genetic alterations in RAS-regulated pathway in acral lentiginous melanoma. Exp Dermatol 2013; 22:148-150.

43 Ashida A, Uhara $\mathrm{H}$, Kiniwa $\mathrm{Y}$, Oguchi M, Murata $\mathrm{H}$, Goto $\mathrm{Y}$, et al. Assessment of BRAF and KIT mutations in Japanese melanoma patients. J Dermatol Sci 2012; 66:240-242.

44 Jakob JA, Bassett RL Jr, Ng CS, Curry JL, Joseph RW, Alvarado GC, et al. NRAS mutation status is an independent prognostic factor in metastatic melanoma. Cancer 2012; 118:4014-4023.

45 Yun J, Lee J, Jang J, Lee EJ, Jang KT, Kim JH, Kim KM. KIT amplification and gene mutations in acral/mucosal melanoma in Korea. APMIS 2011; 119:330-335

46 Kong Y, Si L, Zhu Y, Xu X, Corless CL, Flaherty KT, et al. Large-scale analysis of KIT aberrations in Chinese patients with melanoma. Clin Cancer Res 2011; 17:1684-1691.

47 Si L, Kong Y, Xu X, Flaherty KT, Sheng X, Cui C, et al. Prevalence of BRAF V600E mutation in Chinese melanoma patients: large scale analysis of BRAF and NRAS mutations in a 432-case cohort. Eur J Cancer 2012; 48:94-100.

48 Greaves WO, Verma S, Patel KP, Davies MA, Barkoh BA, Galbincea JM, et al. Frequency and spectrum of BRAF mutations in a retrospective, singleinstitution study of 1112 cases of melanoma. J Mol Diagn 2013; 15:220-226.

49 Handolias D, Hamilton AL, Salemi R, Tan A, Moodie K, Kerr L, et al. Clinical responses observed with imatinib or sorafenib in melanoma patients expressing mutations in KIT. Br J Cancer 2010; 102:1219-1223.

50 Handolias D, Salemi R, Murray W, Tan A, Liu W, Viros A, et al. Mutations in KIT occur at low frequency in melanomas arising from anatomical sites associated with chronic and intermittent sun exposure. Pigment Cell Melanoma Res 2010; 23:210-215.

51 Terada T. Low incidence of KIT gene mutations and no PDGFRA gene mutations in primary cutaneous melanoma: an immunohistochemical and molecular genetic study of Japanese cases. Int J Clin Oncol 2010; 15:453-456.

52 Torres-Cabala CA, Wang WL, Trent J, Yang D, Chen S, Galbincea J, et al. Correlation between KIT expression and KIT mutation in melanoma: a study of 173 cases with emphasis on the acral-lentiginous/mucosal type. Mod Pathol 2009; 22:1446-1456.

53 Ashida A, Takata M, Murata H, Kido K, Saida T. Pathological activation of KIT in metastatic tumors of acral and mucosal melanomas. Int J Cancer 2009; 124:862-868.

54 Curtin JA, Pinkel D, Bastian BC. Absence of PDGFRA mutations in primary melanoma. J Invest Dermatol 2008; 128:488-489.

55 Akslen LA, Puntervoll H, Bachmann IM, Straume O, Vuhahula E, Kumar R, Molven A. Mutation analysis of the EGFR-NRAS-BRAF pathway in melanomas from black Africans and other subgroups of cutaneous melanoma. Melanoma Res 2008; 18:29-35.

56 Beadling C, Jacobson-Dunlop E, Hodi FS, Le C, Warrick A, Patterson J, et al. KIT gene mutations and copy number in melanoma subtypes. Clin Cancer Res 2008; 14:6821-6828.

57 Takata M, Lin J, Takayanagi S, Suzuki T, Ansai S, Kimura T, et al. Genetic and epigenetic alterations in the differential diagnosis of malignant melanoma and spitzoid lesion. Br J Dermatol 2007; 156:1287-1294.

58 Takata M, Goto Y, Ichii N, Yamaura M, Murata H, Koga $\mathrm{H}$, et al. Constitutive activation of the mitogen-activated protein kinase signaling pathway in acral melanomas. J Invest Dermatol 2005; 125:318-322.

59 Liu W, Kelly JW, Trivett M, Murray WK, Dowling JP, Wolfe R, et al. Distinct clinical and pathological features are associated with the BRAF(T1799A (V600E)) mutation in primary melanoma. J Invest Dermatol 2007; 127:900-905.

60 Davison JM, Rosenbaum E, Barrett TL, Goldenberg D, Hoque MO, Sidransky D, Westra WH. Absence of V599E BRAF mutations in desmoplastic melanomas. Cancer 2005; 103:788-792.

61 Lang J, MacKie RM. Prevalence of exon 15 BRAF mutations in primary melanoma of the superficial spreading, nodular, acral, and lentigo maligna subtypes. J Invest Dermatol 2005; 125:575-579.

62 Sasaki Y, Niu C, Makino R, Kudo C, Sun C, Watanabe H, et al. BRAF point mutations in primary melanoma show different prevalences by subtype. J Invest Dermatol 2004; 123:177-183.

63 Reifenberger J, Knobbe CB, Sterzinger AA, Blaschke B, Schulte KW, Ruzicka T, Reifenberger G. Frequent alterations of Ras signaling pathway genes in sporadic malignant melanomas. Int J Cancer 2004; 109:377-384.

64 Maldonado JL, Fridlyand J, Patel H, Jain AN, Busam K, Kageshita T, et al. Determinants of BRAF mutations in primary melanomas. J Natl Cancer Inst 2003; 95:1878-1890.

65 Griewank KG, Murali R, Puig-Butille JA, Schilling B, Livingstone E, Potrony M, et al. TERT promoter mutation status as an independent prognostic factor in cutaneous melanoma. J Nat/ Cancer Inst 2014; 106:dju246.

66 Woodman SE, Davies MA. Targeting KIT in melanoma: a paradigm of molecular medicine and targeted therapeutics. Biochem Pharmacol 2010; 80:568-574.

67 Baruchel S, Sharp JR, Bartels U, Hukin J, Odame I, Portwine C, et al. A Canadian paediatric brain tumour consortium (CPBTC) phase II molecularly targeted study of imatinib in recurrent and refractory paediatric central nervous system tumours. Eur J Cancer 2009; 45:2352-2359.

68 Ozawa T, Brennan CW, Wang L, Squatrito M, Sasayama T, Nakada M, et al. PDGFRA gene rearrangements are frequent genetic events in PDGFRAamplified glioblastomas. Genes Dev 2010; 24:2205-2218.

69 Bello DM, Dematteo RP, Ariyan CE. The GIST of targeted therapy for malignant melanoma. Ann Surg Oncol 2014; 21:2059-2067.

70 Carvajal RD, Lawrence DP, Weber JS, Gajewski TF, Gonzalez R, Lutzky J, et al. Phase II study of nilotinib in melanoma harboring KIT alterations following progression to prior KIT inhibition. Clin Cancer Res 2015; 21:2289-2296. 